\title{
Customer Inclination on Mobile Wallets With Reference to Google- Pay and PayTM in Bengaluru City
}

\author{
Thirupathi Manickam, Alagappa University, India* \\ (iD) https://orcid.org/0000-0001-7976-6073 \\ Vinayagamoorthi G., Alagappa University, India \\ Gopalakrishnan S., Acharya Institute of Graduate Studies, India \\ Sudha M., Acharya Institute of Graduate Studies, India \\ Mathiraj S. P., Alagappa University, India
}

\begin{abstract}
In this cashless economy era, information and communication technology (ICT) plays a vital role in making payments using various payment modes. The mobile wallet app is an innovative technology for avoiding the usage of physical cash. The mobile wallet records all kinds of transactions with a clear payment reference and makes it accountable for tax payments. There are countless reasons for using mobile wallets, which make service providers confused and leads them to offer unattractive features in the wallet apps, making the offer a failure. This paper attempts to collect the data from the mobile wallet users and provides a clear understanding of the reasons for using mobile wallets. Secondly, the customer preferences towards Google Pay and PayTm are analyzed in detail with primary data collected from mobile wallet users to suggest a model for improving the business. This research was conducted to understand the customers' inclination towards the use of mobile wallets.
\end{abstract}

\section{KEYWORDS}

Cashless Economy, Coinless Payment, Digital India, Mobile Wallet, Unified Payments Interface (UPI)

\section{INTRODUCTION}

"Cash; Pay cash, Theodore. It's safest unless you keep your wallet where someone can pick your pocket.”- Jewel E. Ann, Scarlet Stone

India is one of the fast-developing countries to lead the world's economic growth in the global marketplace. The demonetization of two massive currency notes of Rs.500 and 1000 which helped to minimize corruption and money hoarding to a great extent. After demonetization in India, the government has taken many steps to eliminate corruption and black money, out of which, mobile 
wallet is one among them to solve the issues. The Digital India initiative was implemented with more priority to promote a cashless economy in the country. Digital transactions restrict illegal transactions, black money, and helps develop the economic growth of the country. Mobile wallets are one of the major cashless payment systems emerged in India. After demonetization, mobile wallets became a primary financial instrument to make a cashless payment. Initially, the mobile wallet apps were used only for making the recharge and paying bills, but now the mobile wallets are used to make most of the bank transactions and it even reduced the customer visits drastically. Mobile wallets are operated using Mobile apps that should be installed in android or IOS platforms, and also it should be linked with customers' bank accounts, and mobile numbers.

Nowadays mobile wallets are one of the financial instruments used for making all types of payments, transferring funds, recharging, and receiving the funds through bank accounts. Earlier in retail shops, petty shops, food corner, beverages shops, Bus Travel and other visiting places, customers were facing problems with shoppers to get change currency like one rupee or two rupees and five rupees. But right now this problem has been sorted out with the help of mobile wallets. The consumer adoption and learning of technology used in Digital payment system helps consumers to use e-commerce transactions in their day-to-day life (Dahlberg et al., 2015). At the present time, $\mathrm{m}$-wallets are used to execute several financial transactions. In developing economies, $\mathrm{m}$-wallets offer an opportunity to target a large population. According to the report of Economic Times, PayTm is the leading mobile wallet company shown an annual increase of $435 \%$ in the year 2019 . The National Payments Corporation of India developed the Bharat Interface for Money (BHIM app) for transacting funds directly between the bank accounts (Ghosh, 2017).

\section{REVIEW OF LITERATURE}

Akhila Pai H. (2018) has pointed out that the Government of India initiated the concept of 'Digital India' to increase the usage of internet and mobile wallets which in-turn leading to cashless payments. Anil Kumar.Punna \& Mahesh Kumar. Punna (2017) reveals that mobile banking is an essential instrument for transfer of funds from one account to another. Various payment methods like Debit/ Credit cards, internet banking, mobile banking contributes only upto $10 \%$ of the total payments. According to Pankaj Yadav (2017), The researcher has focused on users from all four directions in India i.e., east, west, north, and south. The data was collected from the customers who all are using the mobile wallet and its benefits/usefulness. The researcher has kept in mind the six factors in existing studies (i.e., perceived quality of service, perceived risk, perceived usefulness, perceived cost, observe ease of use, and trust) which leads to adaptation of mobile wallets. Richa Goel et al. (2019), It is believed that the cashless economy is the key to the Indian economy which helps to restrict the flow of physical cash in the country. Cashless payments are made through virtual and app-based transactions, and it has been widely adopted by the people after the demonetization. Vijayashri Mahindra Gurme (2017), the development of information technology through mobile devices generates novelty called "Mobile Wallet". The invention of mobile wallet payments releases growth and flexibility to banking and financial institutions as well as businesses. FAIR Inc. Inspite of the technological and scientific development in Japan $70 \%$ of the population prefers cash payment over cashless payments. The Government of Japan envisions cashless Japan in the future by encouraging people to use digital payment methods like mobile wallet and online payment systems. From the literature reviewed related to mobile wallets, it was understood that there are no studies that analyze the reasons and competitiveness of PayTm and Google Pay. As on date, only these two wallets companies having large number of customers in India. Another research gap has been addressed in this study is that, many researchers have developed and tested the hypothesis on factors influencing the acceptance of mobiles, but this study concentrates on customers' confidence about the wallets on the basis of Trust, Gain and Accountability. 


\section{PROBLEM STATEMENT}

A mobile wallet is one of the financial inclusion options available to access financial services. When people are running behind time, mobile wallet helps in time saving and helps in quick payments for doing various transactions like travel booking, hotel booking, bill payments and purchases. In India, many Indian and International mobile wallet companies compete to capture the Indian mobile wallet market. Globally, mobile wallet transactions have reached INR 2 trillion in 2019 and the survey revealed that $83.6 \%$ of the respondents are using mobile wallet transactions in India. All the mobile wallet brands are approved by the Reserve Bank of India and both private and public sector banks connect their UPI's with mobile wallets. Especially in Bangalore, most of the employees, students, homemakers, business people, retail shoppers, petty shoppers, and roadside vendors are adopting and using the mobile wallet for their day to day transactions. In India, around 20 brands of mobile wallets are available but in Bangalore, most people prefer PayTm \& Google pay. Attempt is made to analyse the reasons for the success of these two brands of wallets among the various brands in Bangalore. Mobile wallet payments are the most convenient and fastest payment method in cashless payments. The mobile wallet provides more offers and discounts to the users and eliminates the use of banking cards, account numbers, IFSC, and passwords for making the transactions.

\section{RESEARCH OBJECTIVES}

1. To understand the primary reasons for using mobile wallets in Bengaluru city.

2. To analyze the customer preferences towards PayTm and Google Pay Wallets.

3. To analyze the trust and confidence level of PayTm and Google Pay Wallet users.

4. To suggest suitable solutions to the shortcomings identified for better service to the PayTm and Google Pay customers.

\section{METHODOLOGY}

This descriptive study discusses the customer usage on mobile wallets on Google Pay \& PayTm. This research has been carried out with a systematic process like determining the sampling method, collecting data, analyzing the data, identifying the major findings and given the conclusions. Sampling is the process of identifying and choosing samples from the population for conducting research. As the population size is infinite the researchers have adopted snowball sampling under the non-probability sampling methods to collect data from the respondents. The researcher sent the google form and it has reached a heterogeneous group of 200 respondents who have given their opinion by filling the questionnaires. In that around 30 respondents are not using Google Pay, PayTm or both; and so those questionnaire responses were omitted for the data analysis process. At last, the researcher has taken 170 respondents for data analysis who were using PayTm and Google pay or both mobile wallets. The researchers used both primary and secondary data collected from respondents and other resources. Primary data collected with the help of a questionnaire in the form of a google form sent to the users, and the same was forwarded to their contacts. Secondary data was gathered from different sources such as articles published in different journals \& newspapers, published books, periodicals, conference papers, working papers, and websites, etc.

\section{PILOT STUDY \& RELIABILITY ANALYSIS}

The pilot study has been conducted to know the feasibility of doing this research. During the pilot study, pre-test was conducted to measure the questionnaire. Initially the data has been collected from 50 Respondents and analyzed the 23 items generated Cronbach alpha value of 0.842 which could be 
considered as good and acceptable value, so the researcher has proceeded further for data collection and data analysis to be reliable and consistent. The detailed analysis of factor reduction, Cronbach alpha, composite reliability, and average variance extraction were made through pilot study which is shown in Table 7.

\section{RESEARCH HYPOTHESIS}

H1: There is a significant difference between educations level and customers learn to use the mobile wallet apps'

H2: There is a significant relationship between the Trust factor and Accountability in the mobile wallet app

H3: There is a significant relationship between the Accountability and benefits gain in the mobile wallet app

H4: There is a significant relationship between the Trust factor and benefits gain in the mobile wallet app

\section{ANALYSIS AND DISCUSSION}

The data was collected from the users of Paym, Google pay, and both. Totally 170 respondents have participated in this research, and based on their information, the researchers analyzed the data with the help of SPSS and AMOS software.

The above table no: 1 reveals that the demographical factors of mobile wallet users in the Bengaluru rural area. Around 59.4\% of respondents are female, and 51.8\% of the respondents belonging to the age group is 21 to 30 years old, more than two-fifth (42.9\%) of the respondent's educational qualification is post-graduate, and $52.4 \%$ of the respondents are students involved in the study, around $77.1 \%$ of the respondents are using both google pay and PayTm mobile wallet.

The above table no 2 shows the factors of mobile wallet. More than half $(56.5 \%)$ of the respondents have started to use the mobile wallet after the demonetization in India, the majority (40.6\%) of the respondents are telling that their friends recommended the mobile wallet to make the payment or transactions, 55.3\% of the respondents are saying that they had gone through the instruction from the app how to use and make the payments, around $32.9 \%$ of the respondents are trusting mobile wallet in this digital transactions.

Source: Primary data

The table reveals that customers are using mobile wallets for multiple reasons such as; out of 170 respondents, 158 respondents are using the mobile wallet for making easy payments in retail shops or shopping places, and 169 respondents are using the mobile wallet for making recharges to mobile, Dish, Sun direct, etc.., and $100 \%$ of respondents are mobile wallet adopt to transfer funds one to another or bank to bank, customer to the bank, etc.., 94 respondents purpose of using mobile wallet customer don't want to carry the physical cash or physical wallets with them, 112 respondents are using a mobile wallet to exact amount to the shoppers' instance currency changing problems and finally 73 respondents are using mobile wallet are booking tickets in buses, movies, trains, and flights, etc..,

\section{Problems and Issues in Mobile wallet}

There are some issues and problems that are there in the mobile wallet app. Those problems are affecting the users psychologically and emotionally. The upcoming table clearly shows that what are the problems are facing by mobile wallet users and how those problems are turned into issues.

The above tables reveal that $74.7 \%$ of the respondents are said that while making the transactions, sometimes payment failed happened, and also amount has debited from the wallet in PayTm \& Google 
Table 1. Demographical profile

\begin{tabular}{|c|c|c|c|}
\hline Variable & Respondents & Frequency & Percentage \\
\hline \multirow{3}{*}{ Gender } & Male & 101 & 59.4 \\
\hline & Female & 69 & 40.6 \\
\hline & Total & 170 & 100.0 \\
\hline \multirow{5}{*}{ Age } & Up To 20 Years & 22 & 12.9 \\
\hline & 21 to 30 Years & 88 & 51.8 \\
\hline & 31 to 40 Years & 35 & 20.6 \\
\hline & Above 40 Years & 25 & 14.7 \\
\hline & Total & 170 & 100.0 \\
\hline \multirow{6}{*}{ Education } & SSLC & 12 & 7.1 \\
\hline & PUC/HSC & 14 & 8.2 \\
\hline & UG & 54 & 31.8 \\
\hline & PG & 73 & 42.9 \\
\hline & Professional & 17 & 10.0 \\
\hline & Total & 170 & 100.0 \\
\hline \multirow{6}{*}{ Occupation } & Student & 89 & 52.4 \\
\hline & Private Employee & 57 & 33.5 \\
\hline & Government Employee & 8 & 4.7 \\
\hline & Business/ Profession & 10 & 5.9 \\
\hline & Homemaker & 6 & 3.5 \\
\hline & Total & 170 & 100.0 \\
\hline \multirow{4}{*}{ App using } & PayTm & 18 & 10.6 \\
\hline & Google pay & 21 & 12.4 \\
\hline & Both & 131 & 77.1 \\
\hline & Total & 170 & 100.0 \\
\hline
\end{tabular}

Source: Primary Data

pay app. It is a big thing for the wallet companies because it happened due to network problems, bank server problems, and also wallet problems but the customers are not feeling good psychologically.

\section{How much time has taken to refund the debited amount (days)?}

According to the above analysis, once the transactions have failed but money debit from the wallet, that money has to refund by the wallet to the customers. The refund durations are taking the wallet companies 3 to 15 business days but it affects the users.

\section{Have you lost any amount in this app? If yes means how much.}

Out of 127 respondents, 18 respondents debited amount has not credited in their account, customers are lost their money because of using these wallets. And the remaining 10 respondents debited amount has to refund on the second or next time of debited amount. The amount lost from Rs. 1 to 500 from every customer. 
Table 2. Mobile wallet factors

\begin{tabular}{|c|c|c|c|}
\hline Variable & Respondents & Frequency & Percentage \\
\hline \multirow{3}{*}{ Started using the Mobile Wallet Apps } & Before Demonization & 74 & 43.5 \\
\hline & After Demonization & 96 & 56.5 \\
\hline & Total & 170 & 100.0 \\
\hline \multirow{5}{*}{$\begin{array}{l}\text { Recommendations for the usage of } \\
\text { Mobile Wallet }\end{array}$} & Friend & 69 & 40.6 \\
\hline & Peers \& Colleagues & 37 & 21.8 \\
\hline & Shoppers & 36 & 21.2 \\
\hline & Government & 28 & 16.5 \\
\hline & Total & 170 & 100.0 \\
\hline \multirow{4}{*}{ Learning source to use the App } & Instruction from the APP & 94 & 55.3 \\
\hline & Friends taught me & 56 & 32.9 \\
\hline & Helped by existing users & 20 & 11.8 \\
\hline & Total & 170 & 100.0 \\
\hline \multirow{6}{*}{ Preference to choose a wallet } & Unique & 41 & 24.1 \\
\hline & Trustable & 56 & 32.9 \\
\hline & Familiar in Bengaluru & 37 & 21.8 \\
\hline & Brand name & 28 & 16.5 \\
\hline & Share Market Value & 8 & 4.7 \\
\hline & Total & 170 & 100.0 \\
\hline
\end{tabular}

Source: Primary data

Figure 1. Reasons for using mobile wallets

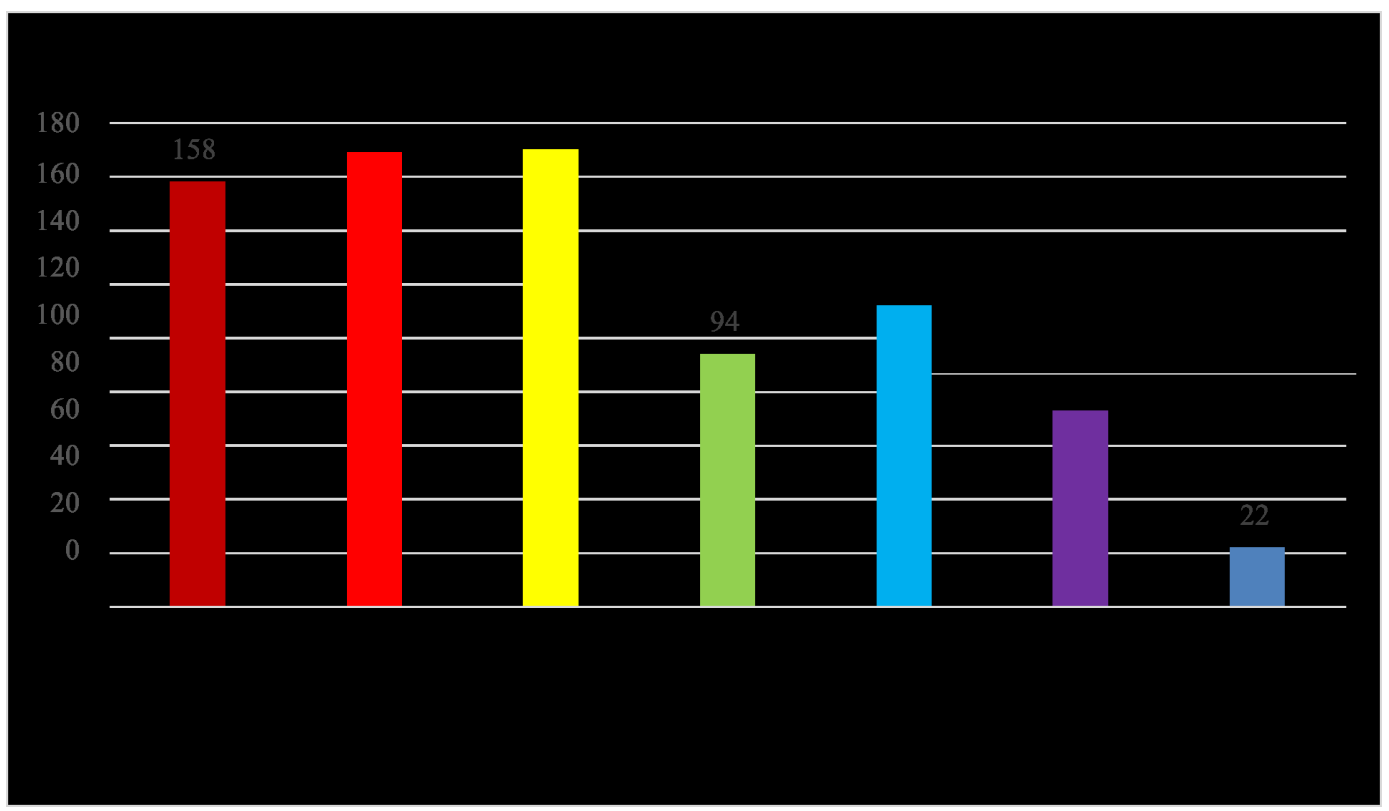


Table 3. Payment failed in App

\begin{tabular}{|l|l|l|}
\hline \multicolumn{1}{|c|}{ Respondents } & \multicolumn{1}{c|}{ Frequency } & \multicolumn{1}{c|}{ Percentage } \\
\hline Happened & 127 & 74.7 \\
\hline Not Happened & 43 & 25.3 \\
\hline Total & 170 & 100.00 \\
\hline
\end{tabular}

Source: Primary Data *(127 Data has attached)

\section{After losing the money have you continue to use this app. If yes means why?}

The customers are continuing the use of the same mobile wallets even though they lost their money because customers' are mentioned that still, they are believing the mobile wallets, easy to use, more convenient, good wallet, and reliable, etc...

\section{Analysis of the Education levels and Customers learning of app usage}

H0: There is no significant difference among the different education levels on customers learning for using the mobile wallet apps'

H1: There is a significant difference among the different education levels on customers learning for using the mobile wallet apps'

The one-way ANOVA table indicates that the significant value is less than the 5\% level of significance, hence it is concluded that the null hypothesis was rejected. There is a significant difference among the different education levels on customer's learning for using the app.

\section{Customer Confidentiality Analysis - Google Pay}

The confidence level about trust, accountability, and gain is analyzed with the help of factor analysis based on the data collected from Google Pay users. Factor analysis is a technique that is used to reduce a large number of variables into fewer numbers factors. This technique extracts maximum common variance from all variables and puts them into a common score. Here are the 12 variables with Likert scale type questions on user's opinions towards Google pay mobile wallet.

From the above table the extraction sums, associated with each linear component to determine the factor analysis "preference on google pay wallet" are rotated. All the 12 factors have been divided into 3 components with greater than 1 . The rotated component shows a cumulative percentage of $68.968 \%$ of the total variance explained by the three common factors.

From the table in factor analysis, factors are divided into three components, under the first component variables are; Not Charging transaction fees in the Google pay app, the third party can't access your account in Google pay app, Google pay to provide security lock, Google pay is safest

Table 4. ANOVA

\begin{tabular}{|c|c|c|c|c|c|}
\hline \multicolumn{6}{|c|}{ ANOVA } \\
\hline Education & Sum of Squares & Df & Mean Square & $\mathbf{F}$ & Sig. \\
\hline Between Groups & 2.584 & 2 & 1.292 & \multirow[t]{3}{*}{1.697} & \multirow[t]{3}{*}{.048} \\
\hline Within Groups & 127.187 & 167 & 0.761 & & \\
\hline Total & 129.771 & 169 & & & \\
\hline
\end{tabular}

Source: Primary Data 
Table 5. Total variance explained

\begin{tabular}{|c|c|c|c|c|c|c|c|c|c|}
\hline \multicolumn{10}{|c|}{ Total Variance Explained } \\
\hline \multirow{2}{*}{ Component } & \multicolumn{3}{|c|}{ Initial Eigenvalues } & \multicolumn{3}{|c|}{$\begin{array}{c}\text { Extraction Sums of Squared } \\
\text { Loadings }\end{array}$} & \multicolumn{3}{|c|}{$\begin{array}{c}\text { Rotation Sums of Squared } \\
\text { Loadings }\end{array}$} \\
\hline & Total & $\begin{array}{c}\% \text { of } \\
\text { Variance }\end{array}$ & $\begin{array}{c}\text { Cumulative } \\
\%\end{array}$ & Total & $\begin{array}{c}\% \text { of } \\
\text { Variance }\end{array}$ & $\begin{array}{c}\text { Cumulative } \\
\%\end{array}$ & Total & $\begin{array}{c}\% \text { of } \\
\text { Variance }\end{array}$ & $\underset{\%}{\text { Cumulative }}$ \\
\hline 1 & 5.311 & 44.261 & 44.261 & 5.311 & 44.261 & 44.261 & 3.613 & 30.107 & 30.107 \\
\hline 2 & 1.608 & 13.404 & 57.665 & 1.608 & 13.404 & 57.665 & 2.966 & 24.720 & 54.826 \\
\hline 3 & 1.356 & 11.303 & 68.968 & 1.356 & 11.303 & 68.968 & 1.697 & 14.142 & 68.968 \\
\hline 4 & 0.865 & 7.207 & 76.176 & & & & & & \\
\hline 5 & 0.699 & 5.822 & 81.997 & & & & & & \\
\hline 6 & 0.517 & 4.309 & 86.306 & & & & & & \\
\hline 7 & 0.487 & 4.054 & 90.361 & & & & & & \\
\hline 8 & 0.323 & 2.694 & 93.055 & & & & & & \\
\hline 9 & 0.279 & 2.324 & 95.379 & & & & & & \\
\hline 10 & 0.240 & 2.000 & 97.379 & & & & & & \\
\hline 11 & 0.189 & 1.572 & 98.951 & & & & & & \\
\hline 12 & 0.126 & 1.049 & 100.000 & & & & & & \\
\hline
\end{tabular}

Source: Primary Data

\section{Table 5. Rotated component matrix}

\begin{tabular}{|l|l|l|l|}
\hline \multicolumn{1}{|c|}{ Particulars } & \multicolumn{3}{c|}{ Component } \\
\cline { 2 - 4 } & \multicolumn{1}{|c|}{$\mathbf{1}$} & \multicolumn{1}{c|}{$\mathbf{2}$} \\
\hline Not Charging transaction fee in the Google pay app & 0.851 & -0.031 & 0.103 \\
\hline Third-party can't access your account in the Google pay app & 0.836 & -0.103 & 0.186 \\
\hline Google pay providing security lock & 0.727 & 0.392 & 0.245 \\
\hline Google pay is safest payment app & 0.707 & 0.449 & 0.256 \\
\hline Google pay is very easy to use & 0.685 & 0.367 & 0.266 \\
\hline Providing details of payment & 0.385 & 0.767 & 0.086 \\
\hline Google pay is providing payment reference & 0.316 & 0.761 & 0.142 \\
\hline Server problem is happening more in the Google pay app & -0.148 & 0.744 & -0.121 \\
\hline Payment confirmation Notification & 0.450 & 0.726 & 0.079 \\
\hline Refund the failed payment & 0.426 & 0.551 & -0.034 \\
\hline Getting more offers from google pay & 0.150 & -0.054 & 0.843 \\
\hline Received discounts from google pay & -0.134 & 0.094 & 0.834 \\
\hline $\begin{array}{l}\text { Extraction Method: Principal Component Analysis. } \\
\text { Rotation Method: Varimax with Kaiser Normalization. }\end{array}$ & & & \\
\hline a. Rotation converged in 6 iterations. & & & \\
\hline Sorce -Pringy Data & & & \\
\hline
\end{tabular}

Source - Primary Data 
payment app, Google pay is very easy to use are named as Trust on mobile wallets. Whereas under the second component are; Providing details of payment, Google pay is providing payment references, Server problem is happening more in the Google pay app, Server problem is happening more in Google pay app, Refund the failed payment is named as Accountability in the mobile wallet. The remaining variables are; Getting more offers from google pay, received discounts from google pay are named Gain in Mobile wallet.

\section{Confirmatory Factor Analysis [CFA] Model}

The three predictors of this model are Trust, Accountability, and Gain which are the covariates of prefer to choose Google Pay Wallet. The unstandardized estimates model demonstrates regression weights, covariance, and variances. The standardized estimates model demonstrates standardized regression weights.

The goodness of fit is given for the model being tested (the default model), for the saturated model (the just-identified model), and for the independence model (all correlations among variables are zero). The fit of the default model will lie somewhere between the extremes represented by the other two models. In other words, a comparative interpretation is called for. The first index we refer to is CMIN is 127.824 and DF is 51 , the value is 2.506 which indicates the fitness of the model the likelihood ratio Chi-Square. The value of NFI is 0.892 and CFI 0.930 (normally it should be between 0 to 1 ) which reveals that this model is quite good and fit. Then another set of fit statistics refers that the RMSEA (root mean square error of approximation) index is one of several measures that evaluate the extent to which a model fails to fit the data per degree of freedom, and tends to favor more complex models. It is considered a mediocre fit (0.094) Which suggests that the fit is very good. There is much-competing goodness of fit indices to choose from and, as no one index is considered preferable in all respects, it is usual to consider a number. If the indices all lead to the same conclusion, it can be reasonably confident in selecting three representing different types, in a report of the results of a path analysis. The relationship between the Trust and Accountability of Google Pay mobile wallet is (H2:0.73) positively correlated, whereas Accountability and Gain Google Pay mobile wallet is (H3:0.51) positively correlated, Trust and Gain Google Pay mobile wallet is (H4:0.62) positively correlated.

\section{Composite Reliability (CR), Average Variance Extracted (AVE), Maximum Shared Variance (MSV);}

The reliability value $(C R>0.7)$ indicates through Gain: 0.882 , Accountability: 0.835 , and Trust: 0.778 , which means all three factors are more suitable for CFA. The Convergent Validity value (AVE > 0.5 ), based above table the Gain -0.789 , Accountability- 0.520 , and Trust 0.528 , which fulfill the above constructs.

Table 6. Goodness-of-fit indicators of confirmatory factory analysis

\begin{tabular}{|c|c|c|c|}
\hline Particulars & $\begin{array}{l}\text { Calculated } \\
\text { Value }\end{array}$ & $\begin{array}{l}\text { Recommend } \\
\text { value }\end{array}$ & Reference \\
\hline C-Min & 127.824 & \multirow{3}{*}{$<3$} & \multirow{3}{*}{ (Ingram et al., 2000) } \\
\hline Degrees of Freedom(d.f.) & 51 & & \\
\hline C-Min / d.f. & 2.506 & & \\
\hline $\begin{array}{l}\text { Root Mean Square Error of } \\
\text { Approximation (RMSEA) }\end{array}$ & 0.094 & $<0.8$ & (Hu \& Bentler, 1999) \\
\hline Comparative Fit Index (CFI) & 0.930 & $>0.9$ & (Bentler \& Dudgeon, 1996) \\
\hline Normalized Fit Index (NFI) & 0.892 & $>0.8$ & (Bentler \& Dudgeon, 1996) \\
\hline
\end{tabular}


Table 7. Factor loadings

\begin{tabular}{|c|c|c|c|c|}
\hline Constructs & Variables & Factor & AVE & CR \\
\hline \multirow{5}{*}{ Trust } & $\mathrm{T} 1$ & 0.851 & \multirow{5}{*}{0.528} & \multirow{5}{*}{0.778} \\
\hline & $\mathrm{T} 2$ & 0.836 & & \\
\hline & $\mathrm{T} 3$ & 0.727 & & \\
\hline & $\mathrm{T} 4$ & 0.707 & & \\
\hline & $\mathrm{T} 5$ & 0.685 & & \\
\hline \multirow{5}{*}{ Accountability } & A1 & 0.767 & \multirow{5}{*}{0.52} & \multirow{5}{*}{0.835} \\
\hline & A2 & 0.761 & & \\
\hline & A3 & 0.744 & & \\
\hline & A4 & 0.726 & & \\
\hline & A5 & 0.551 & & \\
\hline \multirow{2}{*}{ Gain } & G1 & 0.721 & \multirow{2}{*}{0.789} & \multirow{2}{*}{0.882} \\
\hline & $\mathrm{G} 2$ & 0.649 & & \\
\hline
\end{tabular}

Source: Primary data

Table 8. Model fit for gain, accountability, and trust in the use of mobile- wallet

\begin{tabular}{|l|c|c|c|l|l|l|c|}
\hline & CR & AVE & MSV & MaxR(H) & \multicolumn{1}{|c|}{ Gain } & Accountability & Trust \\
\hline Gain & 0.882 & 0.789 & 0.379 & 0.882 & $\mathbf{0 . 8 8 8}$ & & \\
\hline Accountability & 0.835 & 0.520 & 0.533 & 0.894 & -0.511 & $\mathbf{0 . 7 2 1}$ & \\
\hline Trust & 0.778 & 0.528 & 0.533 & 0.934 & -0.616 & 0.730 & $\mathbf{0 . 6 9 4}$ \\
\hline
\end{tabular}

\section{Customer Confidentiality Analysis}

Data collected from the PAYTM customers are analyzed to understand the confidence level of the customers regarding trust, accountability, and risk factors of the PAYTM app. Factor analysis is a technique that is used to reduce a large number of variables into fewer numbers factors. This technique extracts maximum common variance from all variables and puts them into a common score. Here are the 11 variables with Likert scale type questions on the user's opinion towards PayTm mobile wallet.

From the above table the extraction sums, associated with each linear component to determine the factor analysis "preference on google pay wallet" are rotated. All the 11 variables have been divided into 3 components with greater than 1 . The rotated component shows a cumulative percentage of $67.126 \%$ of the total variance explained by the three common factors.

From the table in factor analysis, factors are divided into three components, under the first component variables are; Getting more offers \& Discounts from PayTm App, PayTm is providing payment reference, PayTm providing the details of payment, Payment confirmation notification, and Refunded the failed payment are named as Accountability in the mobile wallet. Whereas under the second component are; PayTm is the safest payment, PayTm providing a security lock, PayTm is very easy to use are named Trust. The remaining variables are; Third-party can access your account in PayTm Charging transaction fee, Server problem is happening more in PayTm app are named Risk in Mobile wallet.

Partial correlation is a measure of the strength and direction of the linear relationship between three continuous variables whilst controlling for the effect of one or more other continuous variables 


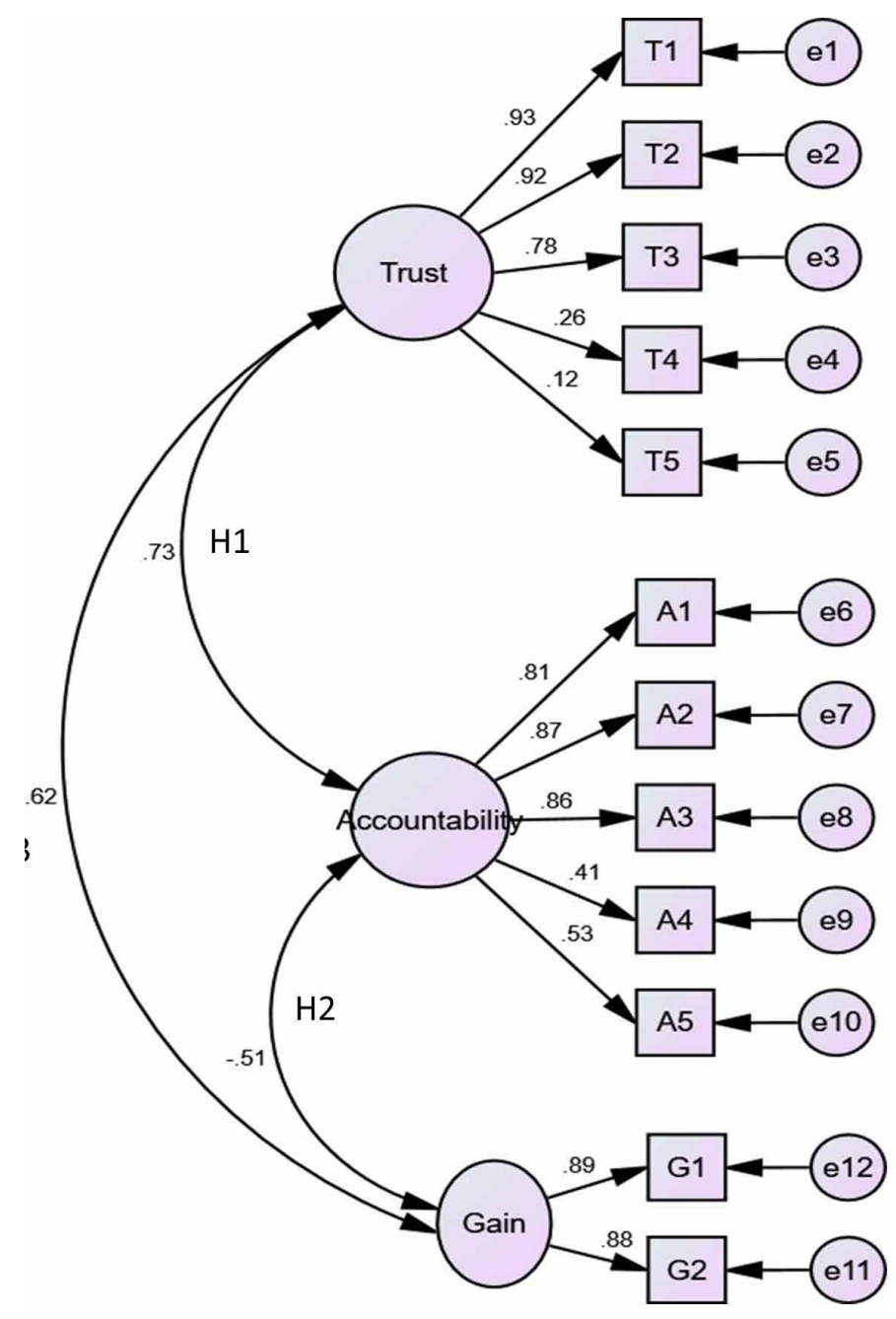

also known as covariate and control variables. Here continue variables are Trust, Accountability, and Risk in PayTm Mobile wallet. The controlling variable is the preference of the mobile wallet. There are a positive correlation .326 relationships found in between the Trust on Wallet and Accountability, and little negatively correlated (-0.001) Trust and Risk. it means the Trust and Accountability factors prefer to choose the mobile wallet. Whereas the Accountability and Risk positive correlation (0.193) relationships found in between the Accountability and Risk of Mobile wallet.

\section{SUMMARY FINDINGS}

- Mobile wallets are used by well-educated people and who know the English language.

- Most people have started using the mobile wallet payment app after demonetization only, hence, the intention of the government is getting fulfilled.

- The majority of the respondents are using the mobile wallet for multiple reasons like doing Recharge, Making Transactions, and making easy payments, etc...but very few of them using the mobile 
Table 9. Total variance explained

\begin{tabular}{|c|c|c|c|c|c|c|c|c|c|}
\hline \multicolumn{10}{|c|}{ Total Variance Explained } \\
\hline \multirow{2}{*}{ Component } & \multicolumn{3}{|c|}{ Initial Eigenvalues } & \multicolumn{3}{|c|}{$\begin{array}{c}\text { Extraction Sums of Squared } \\
\text { Loadings }\end{array}$} & \multicolumn{3}{|c|}{$\begin{array}{c}\text { Rotation Sums of Squared } \\
\text { Loadings }\end{array}$} \\
\hline & Total & $\begin{array}{c}\% \text { of } \\
\text { Variance }\end{array}$ & $\underset{\%}{\text { Cumulative }}$ & Total & $\begin{array}{c}\% \text { of } \\
\text { Variance }\end{array}$ & $\underset{\%}{\text { Cumulative }}$ & Total & $\begin{array}{c}\% \text { of } \\
\text { Variance }\end{array}$ & $\underset{\%}{\text { Cumulative }}$ \\
\hline 1 & 4.020 & 36.545 & 36.545 & 4.020 & 36.545 & 36.545 & 3.273 & 29.754 & 29.754 \\
\hline 2 & 1.895 & 17.227 & 53.772 & 1.895 & 17.227 & 53.772 & 2.298 & 20.889 & 50.642 \\
\hline 3 & 1.469 & 13.353 & 67.126 & 1.469 & 13.353 & 67.126 & 1.813 & 16.483 & 67.126 \\
\hline 4 & 1.000 & 9.088 & 76.213 & & & & & & \\
\hline 5 & 0.664 & 6.036 & 82.249 & & & & & & \\
\hline 6 & 0.447 & 4.065 & 86.314 & & & & & & \\
\hline 7 & 0.415 & 3.770 & 90.084 & & & & & & \\
\hline 8 & 0.360 & 3.277 & 93.361 & & & & & & \\
\hline 9 & 0.304 & 2.762 & 96.123 & & & & & & \\
\hline 10 & 0.250 & 2.272 & 98.395 & & & & & & \\
\hline 11 & 0.177 & 1.605 & 100.000 & & & & & & \\
\hline
\end{tabular}

Source: Primary Data

\section{Table 10. Rotated component matrix}

\begin{tabular}{|c|c|c|c|}
\hline \multicolumn{4}{|c|}{ Rotated Component Matrix } \\
\hline \multirow{2}{*}{ Variables } & \multicolumn{3}{|c|}{ Component } \\
\hline & 1 & 2 & 3 \\
\hline Getting more offers \& Discounts from PayTm & 0.881 & 0.125 & 0.035 \\
\hline PayTm is providing payment reference & 0.880 & 0.121 & 0.103 \\
\hline PayTm providing the details of payment & 0.839 & 0.090 & 0.167 \\
\hline Payment confirmation notification & 0.722 & 0.246 & -0.070 \\
\hline Refunded the failed payment & 0.570 & 0.188 & 0.418 \\
\hline PayTm is safest payment & 0.126 & 0.857 & 0.075 \\
\hline PayTm providing security lock & 0.125 & 0.850 & 0.073 \\
\hline PayTm is very easy to use & 0.251 & 0.809 & -0.090 \\
\hline Third-party can access your account in PayTm & -0.123 & -0.073 & 0.865 \\
\hline Charging transaction fee & 0.228 & -0.113 & 0.750 \\
\hline Server problem is happening more in PayTm app & 0.100 & 0.180 & 0.514 \\
\hline \multicolumn{4}{|c|}{$\begin{array}{l}\text { Extraction Method: Principal Component Analysis. } \\
\text { Rotation Method: Varimax with Kaiser Normalization. }\end{array}$} \\
\hline a. Rotation converged in 5 iterations. & & & \\
\hline
\end{tabular}

Source: Primary Data 


\begin{tabular}{|c|c|c|c|c|c|}
\hline \multicolumn{6}{|c|}{ Correlations } \\
\hline \multicolumn{3}{|c|}{ Control Variables } & Trust & Accountability & Risk \\
\hline \multirow{9}{*}{$\begin{array}{l}\text { Preference } \\
\text { of Mobile } \\
\text { Wallet }\end{array}$} & \multirow{3}{*}{ Trust } & Correlation & 1.000 & 0.326 & -0.001 \\
\hline & & Significance (2-tailed) & & 0.000 & 0.994 \\
\hline & & Df & 0 & 166 & 166 \\
\hline & \multirow{3}{*}{ Accountability } & Correlation & 0.326 & 1.000 & 0.193 \\
\hline & & Significance (2-tailed) & 0.000 & & 0.012 \\
\hline & & Df & 166 & 0 & 166 \\
\hline & \multirow{3}{*}{ Risk } & Correlation & -0.001 & 0.193 & 1.000 \\
\hline & & Significance (2-tailed) & 0.994 & 0.012 & \\
\hline & & Df & 166 & 166 & 0 \\
\hline
\end{tabular}

Source: Primary Data

wallet for online shopping purposes. The awareness level of online shopping options available with PayTm is very less.

- The majority of the respondents are telling that while making the transactions, sometimes the transactions are failing, it reduces the reputation of the wallet

- Few consumers have mentioned that they lost their money because of the failed transaction and the money did not come back to their account at all.

- According to the ANOVA test, there is a significant difference between different levels of education that determines how the customers learn to use these mobile wallet apps.

- According to the correlation table, Trust and accountability in PayTm mobile wallet have correlated negatively, it indicates that customers feel that there is a risk in using a mobile wallet, still, they use it because of its benefits.

\section{MANAGERIAL IMPLICATIONS}

The study has the following implications to the Policy makers of PayTm and Google Pay for increasing the promotional aspects of Mobile wallet usage in India. Inclusion of regional languages in a mobile wallet will help to maximize the number of users in India, which would motivate the potential users with lower levels of education. Organizations can also provide a valuable offer for the $1^{\text {st }}$ time install or user of mobile wallet. The tolerance level of servers on the network issues is to be improved as more cases of failed transactions received from the customers. Companies need to put some efforts for quick refund in case of failed transactions and using advanced technologies and higher bandwidth for better connectivity and zero downtime of the servers. The can provide pay Spilt bills option, which can help the customers to use more than one app or partly the wallets and currency. Companies can also offer credit facilities to their loyal customers for very low rate of interest. Apart from that wallet companies can also provide an EMI (Equated monthly Instalment) option in their wallet, which can help the customers buy high-value items with installment scheme payment with the help of the mobile wallet itself. Security is another important concern; wallet companies can include face authentication for high-value transactions. Wallet companies need to introduce RFID (Radio-Frequency Identification) \& NFC (Near-Field Communication) payment methods, it will be more secure to the users without providing card details and other information.

Both PayTm and Google Pay should get into online shopping to tap the huge potential available in the retail market. The companies need to tie up with manufacturers and traders utilizing the existing 
brand and capture the market/customers without much difficulty as the companies already have a huge customer base and customer loyalty. Finally, the PayTm can provide more attractive rewards and offers to their customers to encourage them to continue using PayTm, and Google pay can fix a minimum amount or grade points, minimizing the "Better luck next time" option, based on the type of transactions for which the reward gift can be offered with restrictions on repeated transactions.

\section{CONCLUSIONS}

According to Ms.Pranjali A. Shendge (2017), digital wallets can be easily traceable, so it restricts the illegal transaction of money transfer inturn the black money generation. Richa Goel et al. (2019) states that, many rural people are not aware of the cashless economy and many of the people are having a lack faith and confidence in the mobile wallet. It is one of the facts found in this study, the study attempted to find out the reasons for preferring google pay and PayTm mobile wallet only in Bengaluru city. Before and after the demonetization in India, many mobile wallet brands have emerged and these brands are providing many offers and benefits to cover a wide range of users. In India more than 20 mobile wallet brands are available but a few brands like PayTm, Google Pay, Phonepe, MobiKwik, and Freecharge brands are familiar in India and also are user-friendly to their customers. In Bengaluru, Google pay and PayTm are very familiar and it is used by a wide range of people for the reason that two apps are more trustable, less risky, and more familiar in Bengaluru. Despite experiencing the risks in terms of loss of money, a transaction failure, network issues, server down, etc., customers stick to these two brands Google Pay and PayTm due to their loyalty and other factors like convenience, ease to use, time-saving, and risk-free transactions.

\section{LIMITATIONS AND FUTURE RESEARCH DIRECTION}

Based on the above research work, few limitations were identified which would give direction for upcoming research on mobile wallets. The study was conducted based on consumers' perception of Google Pay and PayTm mobile wallet users, and the results of the study may not be suitable to be used for other mobile wallets. It is possible that the other mobile wallet app with several technologies along with more benefits would satisfied or prefer a lot.

Hence the number of mobile wallets and users are predominantly increasing in India (Singh $N$, 2017), finding the customers preference based on 170 samples may not represent the Preference of mobile wallet in Bengaluru city. And also our respondents are a small heterogeneous group of the Bengaluru city population, the forthcoming research may analyze the different cultures with homogeneous respondents, which may focus on other dimensions. Another limitation of the study is that the samples were drawn from Bengaluru only. The next level of research with samples collected with a wider scope would give more elaborate results. Furthermore, As the Government of India is promoting and insisting on people to adopt digital inclusion in villages, towns, and cities, the usage of the apps would increase in the future. The success and failure of any innovation not only depend on consumer-related factors but also on the various elements of the ecosystem (Chawla 2019). This includes mobile wallet service providers, technology providers, government bodies, and financial institutions. Future studies can be carried out to study the preference and satisfaction levels of different stakeholders of digital ecosystem. Lastly, as trust and accountability seems to encourage user perception and preference towards mobile wallet adoption. Future researches involving sub-factors of Accountability, Gain, Risk, and trust would provide in-depth results. 


\section{REFERENCES}

Ahuja \& Joshi. (2018). Customer Perception towards Mobile Wallet. IJRDO-Journal of Business Management, 4(1), 52-60.

Akhila Pai, H. (2018). Study on consumer perception towards digital wallets. International Journal of Research and Analytical Reviews, 5(3), 385-391.

Bentler, P. M., \& Dudgeon, P. (1996). Covariance Structure Analysis: Statistical Practice, Theory, and Directions. Annual Review of Psychology, 47(11), 563-592. doi:10.1146/annurev.psych.47.1.563

Campbell. (2017, December). A Study of Customer Innovativeness for the Mobile Wallet Acceptance in Rajasthan. Pacific Business Review International, 10(6), 7-15.

Chawla, D., \& Joshi, H. (2019). Consumer attitude and intention to adopt mobile wallet in India - An empirical study. International Journal of Bank Marketing, 37(7), 1590-1618. 10.1108/IJBM-09-2018-0256

Dahlberg, T., Guo, J., \& Ondrus, J. (2015). A critical review of mobile payment research. Electronic Commerce Research and Applications. .2015.07.006<ALIGNMENT.qj></ALIGNMENT>10.1016/j.elerap

Goel, Sahai, Vinaik, \& Garg. (2019). Moving From Cash to Cashless Economy: A Study of Consumer Perception towards Digital Transactions. International Journal of Recent Technology and Engineering, 8(1), 1220-1226.

Gurme, V. M. (2017, April). A Survey on Customer Acceptance of Mobile Wallet Payments with Reference to Kothrud Area, Pune, India. International Journal of Research in Management, Economics and Commerce, 07(04), 25-28.

$\mathrm{Hu} \&$ Bentler. (1999). Cutoff criteria for fit indexes in covariance structure analysis: Conventional criteria versus new alternatives. Structural Equation Modeling: A Multidisciplinary Journal, 6(1), 1-55. $10.1080 / 10705519909540118$

Ingram, K. L., Cope, J. G., Harju, B. L., \& Wuensch, K. L. (2000). Applying to graduate school: A test of the theory of planned behavior. Journal of Social Behavior and Personality, 15(2), 215-226.

Kanimozhi \& Kamatchi. (n.d.). Security Aspects of Mobile-Based E-Wallet. International Journal on Recent and Innovation Trends in Computing and Communication, 5(6), 1223 - 1228.

Kumar, A. (2017, July). Money Transactions through Mobile (Anywhere, Anytime, Anybody, Any needs). Asian Journal of Research in Banking and Finance, 7(7), 233-239. doi:10.5958/2249-7323.2017.00079.7

Lonare, A., \& Yadav, A. (2018). E-Wallets: Diffusion and Adoption in Indian Economy. Indian Journal of Commerce \& Management Studies, 9(2), 9-16. 10.18843/ijcms/v9i2/02

Madan, K., \& Yadav, R. (2016). Behavioural intention to adopt mobile wallet: a developing country perspective. Journal of Indian Business Research, 8(3), 227-244. 10.1108/JIBR-10-2015-0112

Mathiraj, Deepa, Geeta, \& Devi. (2019). Consumer Acuity On Select Digital Wallets. International Journal of Scientific \& Technology, 8(12), 3551-3556.

Pillai, Sandhya, \& Rejikumar. (2019). Acceptance of mobile payments and UPI technology - Indian context. International Journal Business Forecasting and Marketing Intelligence, 5(3), 371-384.

Podile, V., \& Rajesh, P. (2017, July). Public Perception on Cashless Transactions in India. Asian Journal of Research in Banking and Finance, 7(7), 63-77. doi:10.5958/2249-7323.2017.00069.4

Sharma, G., \& Kulshreshtha, K. (2019). Mobile Wallet Adoption in India: An Analysis. IUP Journal of Bank Management, 18(1), 7-26.

Shendge, Shelar, \& Kapase. (2017). Impact and Importance of Cashless Transaction in India. International Journal of Current Trends in Engineering \& Research, 3(4), 22-28. http://www.ijcter.com

Singh, N., Sinha, N., \& Liébana-Cabanillas, F. J. (2020). Determining factors in the adoption and recommendation of mobile wallet services in India: Analysis of the effect of innovativeness, stress to use and social influence. International Journal of Information Management, 50(October), 191-205. 
Tang, C. Y., Chin, C. L., Law, C. W., Liew, M. C., \& Phua, V. V. (2014). Examining key determinants of mobile wallet adoption intention in Malaysia: An empirical study using the unified theory of acceptance and use of technology 2 models. International Journal of Modelling in Operations Management, 4(3/4), 248-265. doi:10.1504/IJMOM.2014.067383

Unnisa \& Kumari. (n.d.). Impact of Demonetization: Cash To Cashless-A Study Of Select Consumer. IOSR Journal of Business and Management, 34-40.

Yadav, P. (2017). Active Determinants for Adoption of Mobile Wallet. i-Manager's Journal of Management, 12(1), 7-14.

M. Thirupathi, M.Com, M.Phil, B.Ed, TN-SET, KSET, Ph.D., is presently doing his Ph.D. (part-time) in Alagappa University-Karaikudi and also working as an Assistant professor of commerce in Acharya Bangalore Business School, Bangalore which is IACBE, NBA \& NAAC accredited $A$ grade college and he is having more than 5 years of teaching and research experience. He is having 16 citations and $3 h$-Index, and he has published several research papers in Scopus, UGC approved, and leading international journals and presented papers in national and international conferences. His areas of expertise are Financial Accounting, Corporate Accounting, Financial Management, Management Accounting, Taxation, Digital Marketing and Technology Management, and the like.

Vinayagamoorthi G. is an Assistant professor of commerce at Alagappa University at Karaikudi. He is guiding 4 Ph.D. scholars and M.Phil scholars, He is having 16 citations and $3 \mathrm{~h}$-Index, and he has published several research papers in Scopus, UGC approved and leading International journals, and presented papers in national and international conferences. His areas of expertise are Business, General Management.

S. Gopalakrishnan, Head, Research and Development Cell, Project Director [ICSSR] \& Associate Professor, Department of Commerce \& Management, Acharya Institute of Graduate Studies, Bangalore. He has completed a Major Research Project on "Solid Waste Management" funded by ICSSR (Indian Council of Social Sciences Research). Has 25 years of experience including 12 years of industry and 13 years of teaching Management and Commerce subjects. He has International experience of 1 year working in Nigeria as an Assistant Professor, University of UYO, Nigeria. Published more than 30 articles in refereed journals with 48 citations, $h-I N D E X-3$ and i10 INDEX - 1. He is also the Editor and Reviewer for Elsevier and other Journals.

Sudha M. is working as Assistant professor of Management in Acharya Institute of Graduate Studies Bangalore Business, which is NAAC accredited A grade college and she is having more than 14 years teaching and research experience. She is having published several research papers in Scopus, UGC approved and leading international journals and presented papers in national and international conferences.

Mathiraj S. P. is working as professor of Corporate Secretaryship in Alagappa University at Karaikudi. Ten PhDs were awarded under his guidance and presently 6 Ph.D. pursuing their Doctorate degree scholar. He has also guided 46 M.Phil scholars. Currently, he has got 57 citations and $4 \mathrm{~h}$-Index to his credit, and also he has published 61 research papers in Scopus, UGC-approved, and leading International journals, and presented papers in national and international conferences. His areas of expertise are Accounting, Insurance, and Business. 